\title{
Comparison between proposed fuzzy logic and ANFIS for MPPT control for photovoltaic system
}

\author{
Lotfi Farah $^{1}$, Adel Haddouche ${ }^{2}$, Ali Haddouche ${ }^{3}$ \\ ${ }^{1,3}$ Department of Electromécanique Engineering, University BadjiMokhtar Annaba, Algeria \\ ${ }^{2}$ Mine EngineeringDepartment, University LarbitebessiTebessa, Algeria
}

\begin{tabular}{l} 
Article Info \\
\hline Article history: \\
Received Jun 8, 2018 \\
Revised Nov 9, 2018 \\
Accepted Jan 15, 2020 \\
\hline
\end{tabular}

Keywords:

ANFIS Neuro-fuzzy

Maximum Power Point Tracking

PV System

Reduced Fuzzy Logic

\begin{abstract}
In this paper, a maximum power point tracking (MPPT) algorithm for photovoltaic (PV) systems is achieved based on fuzzy logic controller (FLC) and compared with an anfis (neuro-fuzzy) based mppt controller, this method allies the abilities of artificial neural networks in learning and the power of fuzzy logic to handle imprecise data. Both methods are simulated using matlab/ simulink. The choise of power variation and the current variation as inputs of the proposed controllersreducesthe calculation. Both FLC and ANFIS based MPPTare tested in terms of steady state performance and the pv system dynamic.
\end{abstract}

This is an open access article under the CC BY-SA license.

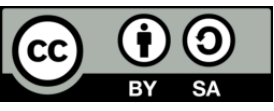

\section{Corresponding Author:}

Lotfi Farah,

Department of Electromécanique Engineering

University BadjiMokhtar Annaba,

Algeria, BP 12 Sidi Amar Road Annaba 23000.

Email: farahlot@yahoo.com

\section{INTRODUCTION}

During the last years, urgent needs for a new energy alternative in order to overcome the energy crisis and global warming issues. Those problems have significantly promoted the renewable energies growth. Undeniably, the photovoltaic systems represent a very competitive solution. Unfortunately, this solution is not perfect due to bad efficiency of the energy conversion; to overcome this problemit isnecessary to provide the PV system with an MPPT controller to gather the maximum electrical power from the photovoltaic modules in different working conditions [1]. Therefore many methods of MPPT were completed in preceding studies, as Perturb and Observe (P\&O) [2], fractional open-circuit voltage [3], fractional shortcircuit current, incremental [3] conductance (IncCon), line approximation, the control of ripple correlation (RCC), PID control, fuzzy logic control (FLC) [2], genetic algorithm [4], neural network and neuro-fuzzy approaches [5]. On the other hand, intelligent systems like FLC, neural network and genetic algorithms are able to determine their parameters, and are capable of operating under highly nonlinear system. In recent years, severaltechniques hybridizations seen theday like the ANFIS (Adaptive Network Fuzzy Inference System) [6]. Their power lies in the possibility of incorporating a knowledge base, dealing withimprecise data by fuzzy logic and introduce learning via the neurons of the network.The response time, overflow and static error criteria can beAssured by conventional control techniques, while the robustness criterionremains a challenge for researchers.Hence, the FLC-based MPPT algorithm attracts many researchers. Freshly in literatures, several MPPT techniques using these techniques were suggested $[2-5,7,8]$. In comparison with $\mathrm{P} \& \mathrm{O}$ algorithm, they provide superior tracking performance. 
To track the maximum power, point this paper proposes a comparison between a Fuzzy Logic Controller with reduced number of rules and ANFIS (Adaptive Network Fuzzy Inference System) controller, this control is imposed by the non-linear characteristics of the PV. Both methods use variation of the power $(\Delta P \mathrm{pv})$ and current variation $(\Delta \mathrm{Ipv})$ as the inputs. Those two methods are tested in terms of steady state performance and the tracking time using MATLAB/Simulink.

\section{MAXIMUM PERFORMANCE POINT TRACKER OPERATION PRINCIPLE}

The connected load characteristics have an important influence on the photovoltaic operating behavior, shown in Figure 1 [9, 10]. For a resistive load, equals Ri, there is only one particular operating point where the optimal adaptation occurs, called the maximum power point (MPP) in our case noticed as $\mathrm{P}$ max, shown in Figure 2. Therefore, if the load and the source are directly connected, it is rarly that the PV module operating point is optimal. To resolve this problematic, a use of an MPPT controller driving a DCDC converter, between the source and the load, is necessary, illustrated in Figure 3 [11]. It is well known that with the temperature and the irradiance variation, the PV system characteristics and its MPP vary corresponding to a curve known as P-V curve, shown in Figure 4 and Figure $5[12,13]$. Thus, to track this variation an MPPT controller has become essential. The last decade, many MPPT control techniques appeared [14, 15]. Classified as follow:

a. Voltage flyback methods (compare the PV operating)

b. PWM signal control generation by the voltage and a reference applied to the DC-DC converter [16].

c. Current flyback methods (use the PV module)

b. - Estimation the MPP current by the short circuit current flyback methods [17].

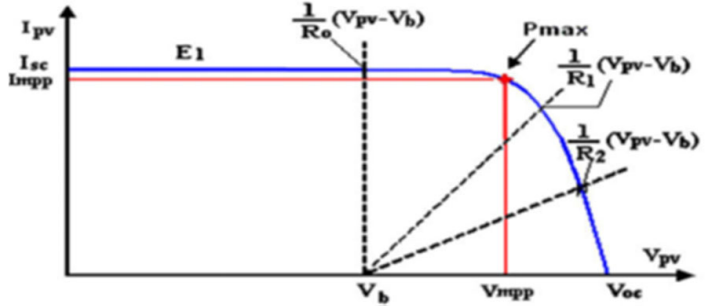

Figure 1. I-V characteristic of the PV module

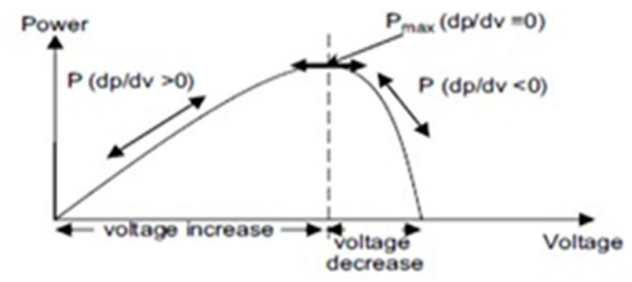

Figure 2. P-V characteristic of the PV module

\section{DC-DC CONVERTER}

In fact, The DC-DC converter is an adaptation between the PV panel and the load. This adaptation is provided by the act on the converter duty cycle (D) ensuring the maximum performance point coincideswith the operating point [18]. Figure 4 illustrates the Boost converter, whose output voltage $(\mathrm{Vb})$ is grater or equal than the input voltage Vi (PV voltage generator) [17].

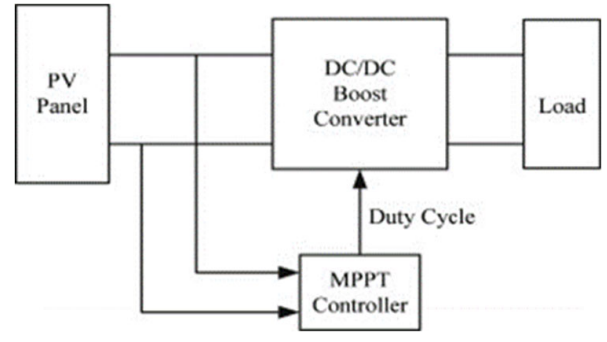

Figure. 3. Photovoltaic system

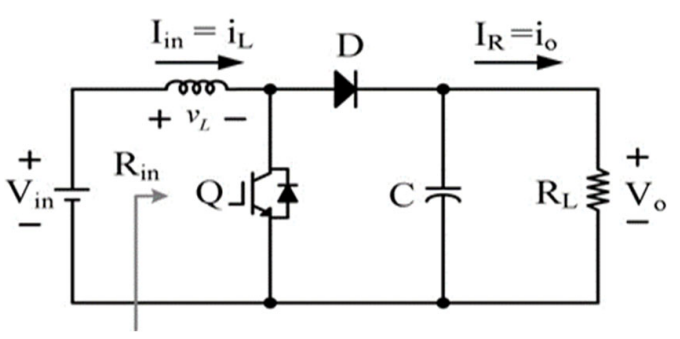

Figure 4. The DC-DC boost converter wiring

The DC-DC boost converter amplifies the voltage and decreases the current in order to maintaine between its input and output a stable power. It is a class of SMPS (Switched-Mode Power Supply) containing minimum two semiconductors (a diode and a transistor) and at any rate one vitality stockpiling component: a 
capacitor, inductor, or on the other hand the two in blend. To decrease voltage ripple, filters made of capacitors (some of the time in mix with inductors) are ordinarily added to such a converter's output (LSF) and input (supply-side filter) [19]. The boost converter can emerge out of any desirable DC sources, for example, batteries, photovoltaic panels, rectifiers and DC generators. A procedure that changes one DC voltage to a different DC voltage is called DC-to-DC conversion [17]. A boost converter is a DC-to-DC converter with a voltage above the voltage of the source. Sometimes a boost converter is called a step-up converter because the source voltage is "stepped up." Due to the need to conserve power $(\mathrm{P}=\mathrm{VI})$, the source current is higher than the load current [20]. The used boost converter's dynamic model, shown in Figure 4.

\section{ANFIS (NEURO-FUZZY) MPPT CONTROLLER}

ANFIS is a combination between fuzzy logics (FL) and the highly interconnected Artificial Neural Network (ANN). In fact, each layer of the ANN uses a function of the FL. The seconde layer uses the Membership function, the thired one uses the rules the fourth one is the sum of the thired layer nodes, the first and the fifth ones are the input and the output layers. ANFIS isthe benefits of both types of machine learning (Fuzzy Logic and Neural Network) into single technique methods. The ANFIS toolbox constructs a fuzzy inference system (FIS) whose membership function parameters are modified using either a backpropagation algorithm or a combination of back propagation algorithm and the least square form of approach (Figure 5). This learning process is called the Hybrid Learning Technique. This enables fuzzy systems to learn from the data they model. ANFIS works by applying Neural Network Learning [21, 22]. ANFIS is known for its remarkable power of, nonlinear mapping, modelling, pattern recognition, and learning [23].

In this paper, the two ANFIS inputs, shown in Figure 6 are: $a$ and b, and the single output is c. the Sugeno fuzzy model, a typical for the rule is set with the fuzzy if-then rules as

Rule: If $x$ is $X$ and $Y$ is $B$, then $c=\left(p^{*} a+q^{*} b+z\right)$.

Where $\mathrm{Xi}$ and $\mathrm{Bi}$ are the fuzzy sets in the antecedent, and $\mathrm{p}, \mathrm{q}$ and other parameters are determined during the training process. ANFIS involvesfive layers, and each layer's nodes depend on the number of inputs, membership function and rules and mostly on a single output. The MATLAB program includes an ANFIS tool used to build the FLC controller, this system utilizes the process of training the ANFIS based on the training data. This data contains vector of the inputs representing the operation temperature and the operation solar irradiation, and as output, the vector that represents the best decision of duty cycle given to the system to run at MPP, illustrated in Figure 7.

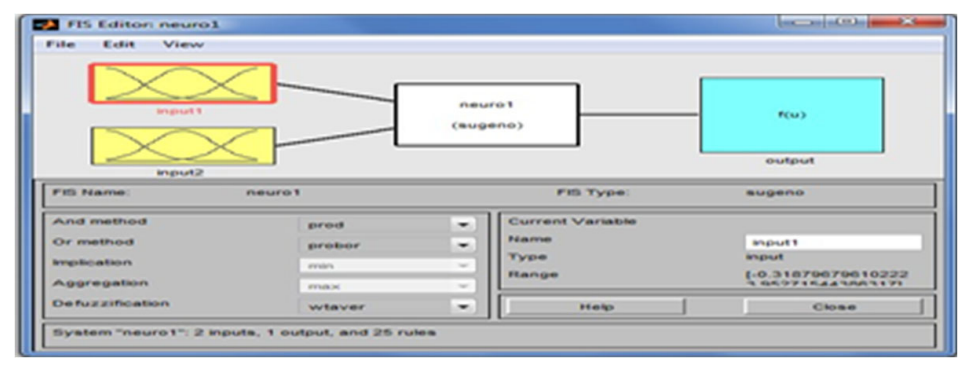

Figure 5. Matlab ANFIS toolbox

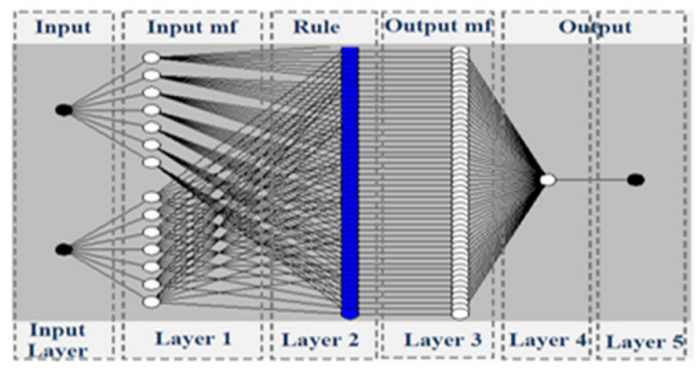

Figure 6. Detailed anfismatlab structure

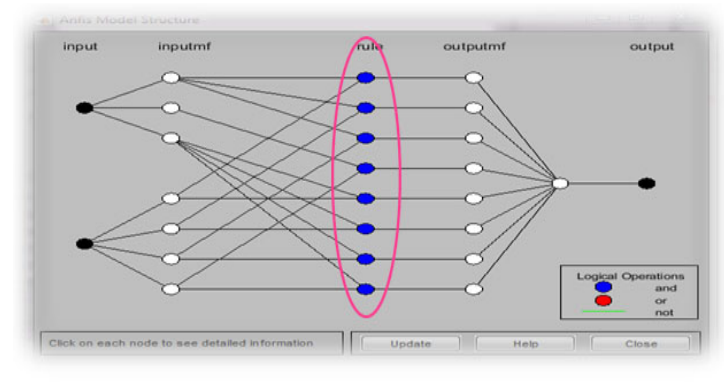

Figure 7. Anfis model 


\section{FUZZY LOGIC MPPT CONTROLLER}

In many new literatures, the fuzzy logic based MPPT command has been used; this robust command does not necessitate exact knowledge of a mathematical system model. The developer, on the other hand, requires complete knowledge of the function of the PV system. The inputs of the theoretical MPPT controller in this paper are the power variance $(\Delta \mathrm{Ppv})$ and the current variation $(\Delta \mathrm{Ipv})$. Influence of the solar radiation for constant temperature is shown in Figure 8. Figure 9 shows the MFs of the input and output variables used for the proposed controller. In Figure 10. The MFs of the input variables; both $\Delta \mathrm{Ppv}$ and $\Delta \mathrm{Ipv}$ are in triangular form Figure 9. The MF of the output (duty cycle step size D), which is also in triangular form Figure 10. In Figure 9, DP means the power variation, DI (current variation) and D (duty cycle variation). The linguistic variables are: P (positive), N (negative), B (big), S(small) and Z(zero). from Figure 9, each of the input variables $\Delta \mathrm{Ppv}$ and $\Delta \mathrm{Ipv}$ are mapped into five different linguistic values. Instead of usual proposed fuzzy system, our model is set with a limited number of rules [17].

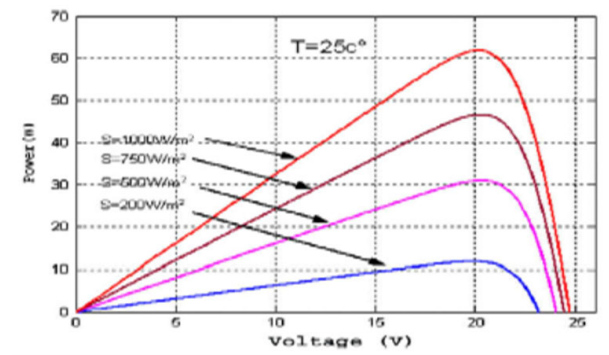

Figure 8. Influence of the solar radiation for constant temperature

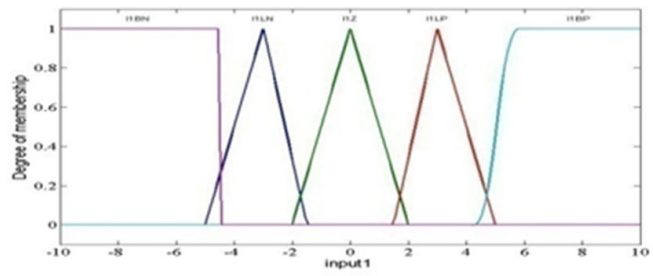

(a)

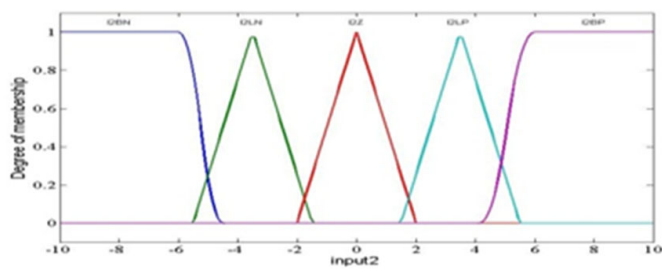

(b)

Figure 9. Membership functions for inputs (a) input1 DPv, (b) input2 DIv

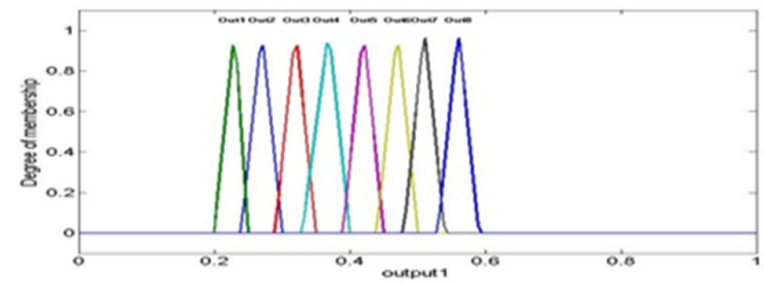

Figure 10. Membership function for output D (duty cycle)

The fuzzy inference uses Mamdani's method. The fuzzy controller structure is shown in figure 11, Table 1, and the defuzzification uses the centre of gravity to calculat the duty cycle, the FLC output, the Table 1 bellow indicates the control rules. 


\begin{tabular}{clcccc}
\multicolumn{5}{c}{ Table 1. Controller rules } \\
\hline & NB & NS & Z & PS & PB \\
\hline NB & BP & & & & \\
NS & PS & & & & \\
Z & & Z & Z & NS & \\
PS & & & NS & NB & Z \\
PB & & & & .
\end{tabular}

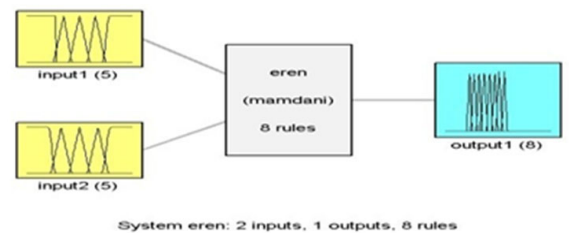

Figure 11. The fuzzy controller structures

\section{IMPLIMENTATION AND RESULTS}

6.1. Implimentation

The proposed FLC and the ANFIS controller have been realised and tested under SIMULINK (MATLAB) to a100-kW Grid-Connected PV Array, shown in Figure 12 (Detailed Model). In this work, changes in solar radiation are applied to assess and check the robustness of the proposed controller [24]. Irradiation pattern is shown in Figure 13 [17], for the PV the model is the SUNPOWER SPR-305-WHT

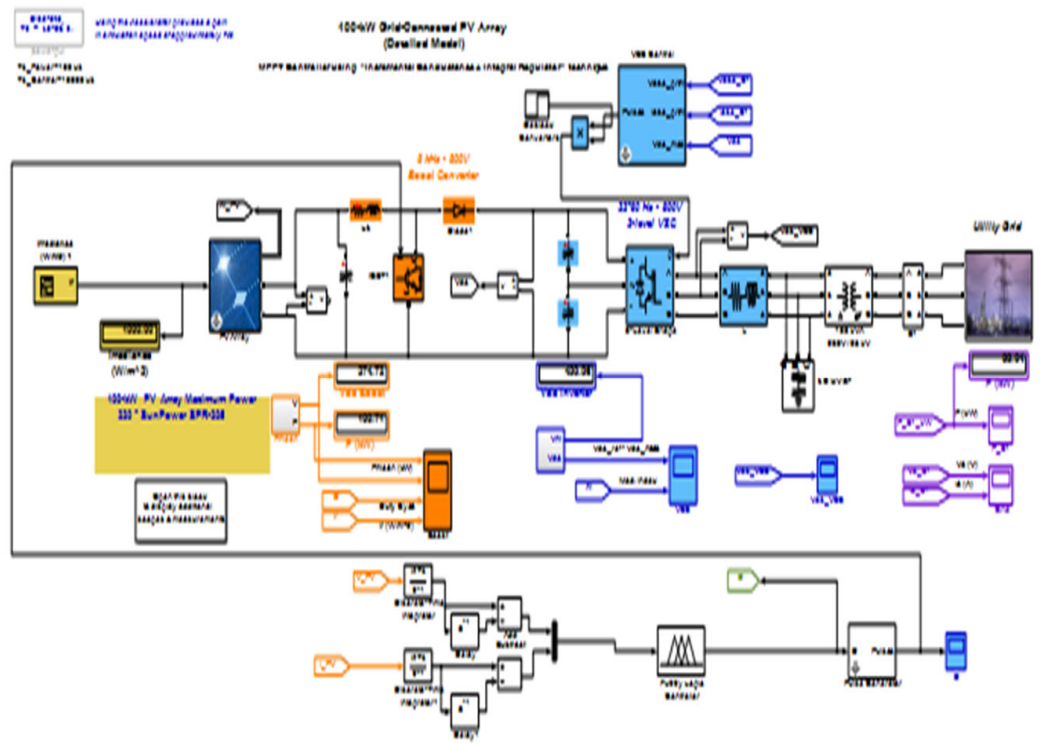

Figure 12. 100-kW Grid-connected PV Array

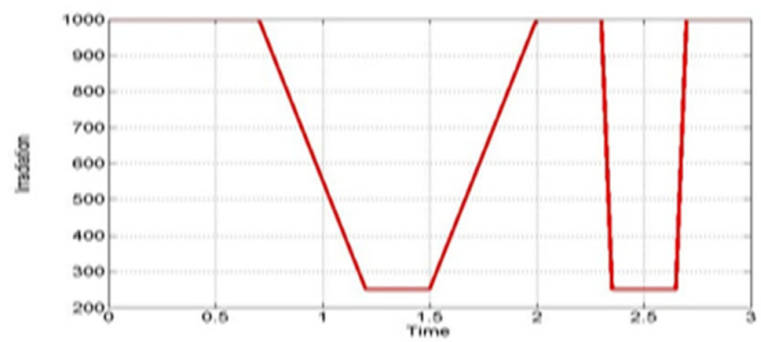

Figure 13. Irradiation pattern

\subsection{Results}

The simulation results for FLC and ANFIS are respectively shown in figures below. Generator output power, shown Figure 14 and Figure 15, operating voltage shows in Figure 16 and Figure 17, operating

Comparison between proposed fuzzy logic and ANFIS for MPPT control for ... (Lotfi Farah) 
current shown in Figure 18 and Figure 19, and the duty ratio shown in Figure 20 and Figure 21 and grid voltage illustrated in Figure 22 and Figure 23. Using a boost converter under standard test conditions has shown that the proposed FLC controller shows better static error, shown in Figure $25(1.62 \mathrm{~kW}$ so $1.62 / 100.71=0.016 \%$ ) [17] and less Tracking time error illustarated in Figure 24 (less than 0.005s) comparing to the ANFIS controller $(1.85 \mathrm{~kW}$ so $1.85 / 100.71=0.020 \%$ static error and $0.011 \mathrm{~s}$ for Tracking time) in Figure 25.

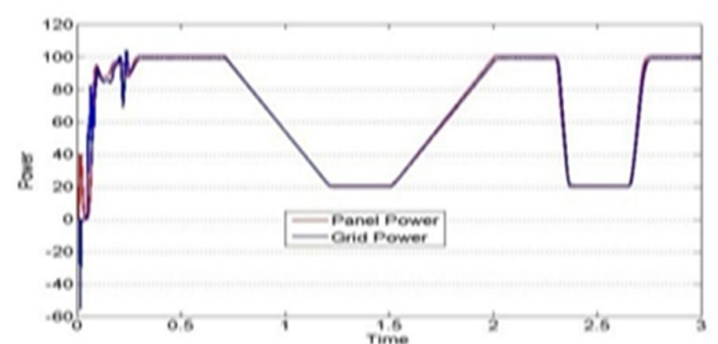

Figure 14. FLC generator output power

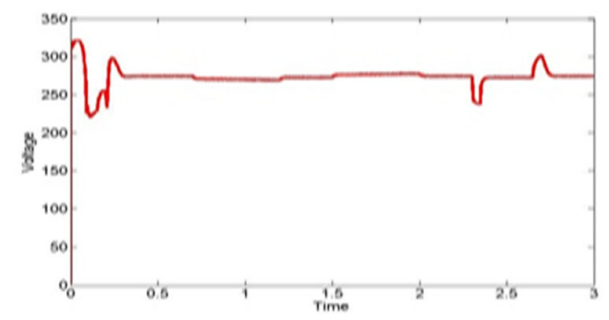

Figure 16. FLC operating voltage

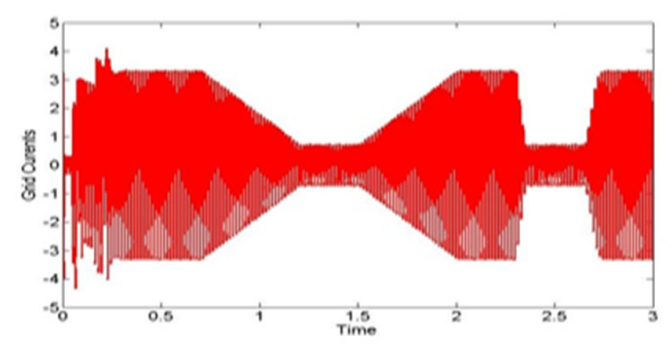

Figure 18. FLC grid currents

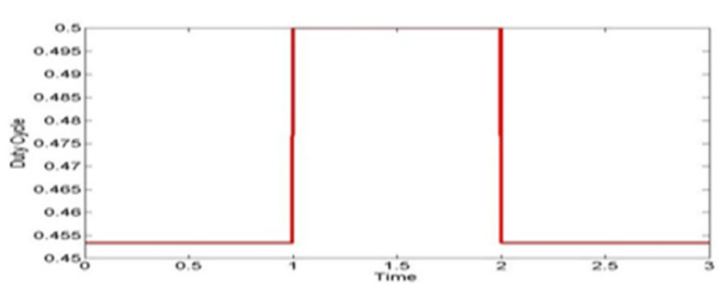

Figure 20. FLC duty cycle

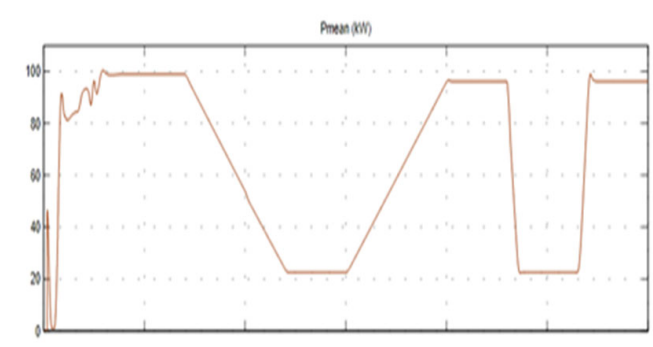

Figure 15. ANFIS panel output power

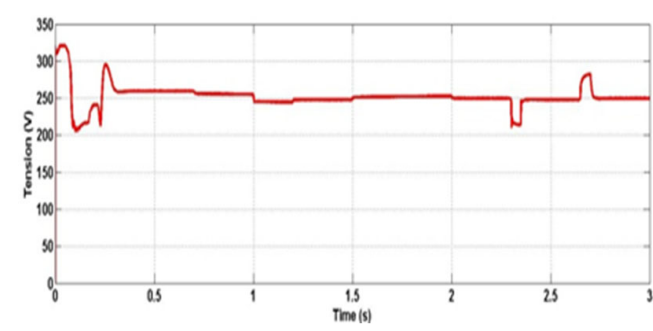

Figure 17. ANFIS operating voltage

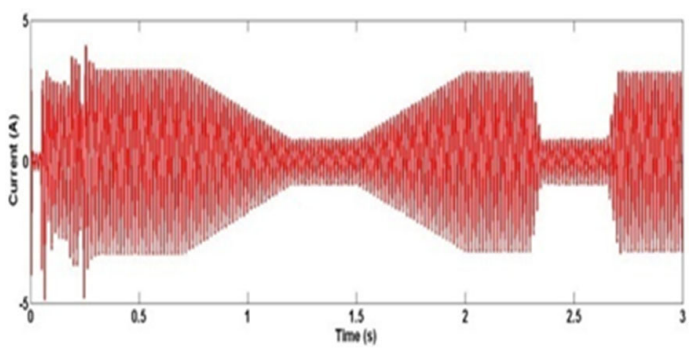

Figure 19. ANFIS grid currents

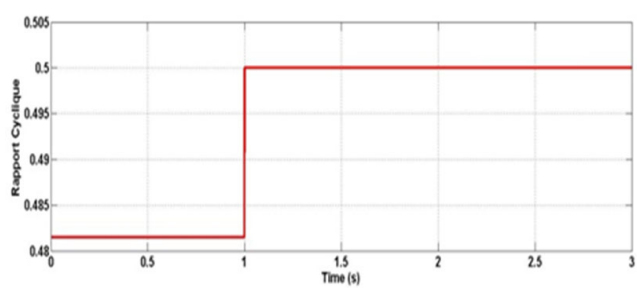

Figure 21. ANFIS duty cycle 


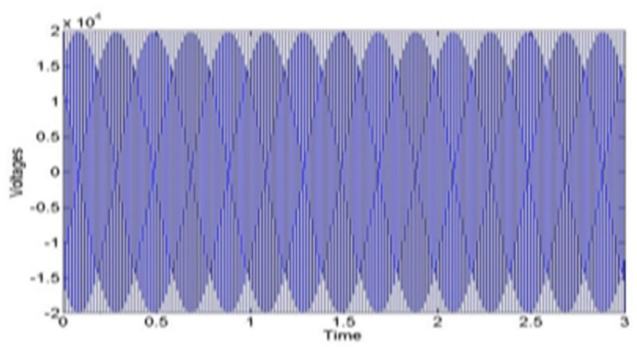

Figure 22. FLC grid voltage

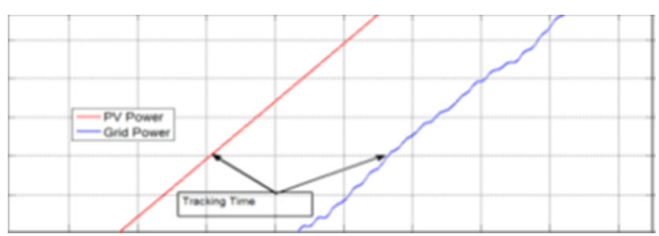

(a)

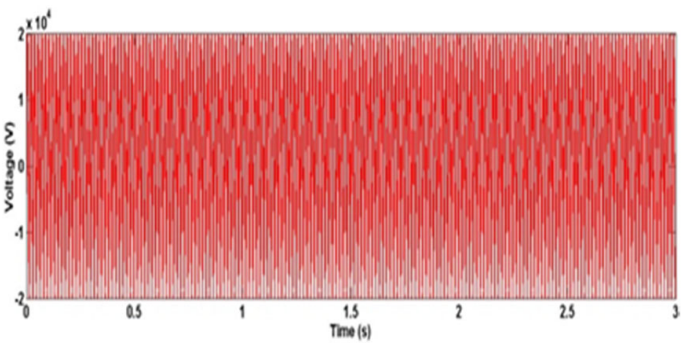

Figure 23. ANFIS grid voltage

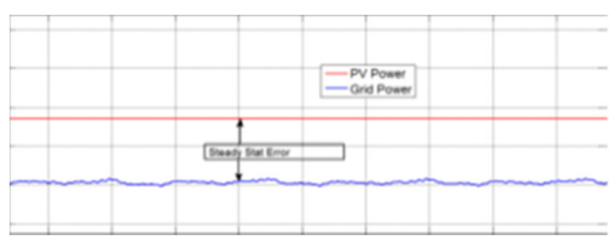

(b)

Figure.24 (a) tracking time calculation method (b) steady state error calculation method

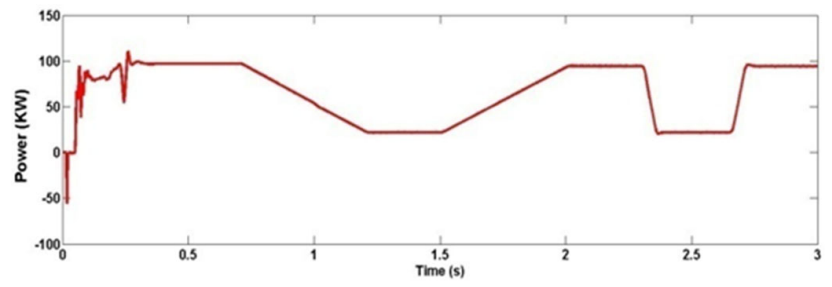

Figure 25. ANFIS grid power output

Table 2. Comparaison between used methods and $\mathrm{P} \& \mathrm{O}$

\begin{tabular}{lcc}
\hline \multicolumn{1}{c}{ Technique } & Vitesse de poursuite & Erreur statique \\
\hline P\&O & $0.015 \mathrm{~s}$ & $0.74 \%$ \\
FLC WithreducedRules & $0.005 \mathrm{~s}$ & $0.016 \%$ \\
ANFIS & $0.011 \mathrm{~s}$ & $0.020 \%$ \\
\hline
\end{tabular}

\section{CONCLUSION}

In this paper, an FLC with reduced number of rules based MPPT and ANFIS based MPPT have been developed and tested in MATLAB/Simulink environment, based on the simulation it can be concluded that with the both controllers the PV panel can deliver the maximum power. However, the performance of fuzzy with reduced rules MPPT is better than ANFIS based MPPT in terms of tracking speed and static error duo to its reduced number of rules (8) instead of conventional (25) which makes it's lighter and improve global performance.

\section{REFERENCES}

[1] Abdelsalam, A.K, Massoud, A.M, Ahmed, S, and Enjeti, P.N, "High-performance adaptive perturb and observe MPPT technique for photovoltaic-based microgrids," IEEE Trans. Power Electron, vol. 26, pp. 1010-1021, 2011

[2] Mohamed Amine Abdourraziq and Mohamed Maaroufi, "Experimental Verification of the Main MPPT Techniques for Photovoltaic System," International Journal of Power Electronics and Drive Systems (IJPEDS), pp. 384-391, 2017.

[3] Shen, C.L; and Tsai, C.T, "Double-linear approximation algorithm to achieve maximum-power-point tracking for photovoltaic arrays," Energies, vol. 5, 1982-1997. 2012. 
[4] Yau, H.T and Wu, C.H, "Comparison of extremum-seeking control techniques for maximum power point tracking in photovoltaic systems," Energies, vol. 4, pp. 2180-2195, 2011.

[5] Yaichi, M., Fellah, M. K, and Mammeri, A, "A neural network based MPPT technique controller for photovoltaic pumping system," International Journal of Power Electronics and Drive Systems (IJPEDS), vol. 4, no. 2, pp. 241$255,2014$.

[6] P. M. Menghal and A. J. Laxmi, "Adaptive Neuro Fuzzy Based Dynamic Simulation OfInduction Motor Drives," in Proceedings of the IEEE International Conference on FuzzySystems (FUZZ'13), pp. 1-8, IEEE, Hyderabad, India, Jul 2013.

[7] Ishaque, K and Salam, Z, "A review of maximum power point tracking techniques of PV system for uniform insolation and partial shading condition," Renew. Sustain. Energy Rev, vol. 19, pp. 475-488, 2013.

[8] Femia, N, Petrone, G, Spagnuolo, G, and Vitelli, M, "Optimization of perturb and observe maximum power point tracking method," IEEE Trans. Power Electron, vol. 20, pp. 963-973, 2005.

[9] Hassaine L, Modélisation et Simulation d'un Système de Conditionnement de Puissance pour la Poursuite de Puissance Maximale dans les Systèmes Photovoltaïques. Alegria: Mémoire de Magister, Ecole Nationale Polytechnique (ENP), Jui 2003.

[10] Lu CF, Liu CC, and Wu CJ, "Dynamic modeling of battery energy storage system and application to power system stability," IEEE Proceedings Generation, Transmission and Distribution, vol. 142, no. 4, pp. 429-35, Jul 1995.

[11] A. A. Siddik and M. Shangeetha, "Implimentation of Fuzzy Logic Controller in photovoltaic Power generation using Boost converter and Boost Inverter," International Journal of Power Electronics and Drive System (IJPEDS), vol. 2, no. 3, pp. 249-256, 2012.

[12] Jena, D and Ramana, V.V, "Modeling of a photovoltaic system for uniform and non-uniform irradiance: A critical review," Renew. Sustain. Energy Rev, vol. 52, pp. 400-417, 2015,

[13] Gottschalg R, Rommel M, Ineld DG, and Ryssel H, "Comparison of different methods for the parameter determination of the solar cell's double exponential equation," In: 14th European photovoltaic science and engineering conference (PVSEC), Barcelona, Spain; 1997.

[14] Salas V, Olias E, Barrado A, and Lazaro A, "Review of the maximum power point tracking algorithms for standalone photovoltaic systems," Solar Energy Materials \& Solar Cells, vol. 90, pp. 1555-78, 2006.

[15] EsramT and Chapman PL, "Comparison of photovoltaic array maximum power point tracking methods," IEEE Transactions on Energy Conversion, vol. 22, no. 2 Jun 2007

[16] Veerachary M, Senjyu T, and Uezato K, "Voltage-based maximum power point tracking control of PV systems," IEEE Transaction on Aerospace and Electronic Systems, vol. 38, 262-70, Jan 2002.

[17] Adel Haddouche, Mohammed Kara, Lotfi Farah, "Maximum Power Point Tracker Using Fuzzy Logic Controller with Reduced Rules," International Journal of Power Electronics and Drive System (IJPEDS), vol. 9, no. 3, pp. 1381-1390, Sep 2018

[18] Coelho RF, Concer FM, Martins D., “A simplified analysis of DC-DC converters applied as maximum power point tracker in photovoltaic systems", 2nd IEEE International Symposium on Power Electronics for Distributed Generation Systems, pp.29-34, 2010.

[19] Erickson RW and Maksimovic D, "Fundamentals of power electronics" 2nd edition, New York: Kluwer Academic Publishers; 2001.

[20] S. Narendiran, Sarat Kumar Sahoo, Raja Das, "Control and Analysis of MPPT Techniques for Maximizing Power Extraction and Eliminating Oscillations in PV System," International Energy Journal, vol. 16, pp. 107-118, 2016.

[21] Pandey, A, Dasgupta, N, and Mukerjee, A.K, "High-performance algorithms for drift avoidance and fast tracking in solar mppt system," IEEE Trans. Energy Convers, vol. 23, pp. 681-689, 2008.

[22] D’Souza, N.S, Lopes, L.A.C, and Liu, X, "Comparative study of variable size perturbation and observation maximum power point trackers for PV systems," Electr. Power Syst. Res, vol. 80, pp. 296-305, 2010.

[23] "Arabic Words Recognition by Fuzzy Classifier," Journal of Applied Sciences, vol. 6, no. 3, Mar 2006.

[24] Hua C and Shen C, "Control of DC/DC converters for solar energy system with maximum power tracking," 23rd Int Conference on Industrial Electronics, Control and Instrumentation (IECON 97), pp.827-32, 9-14 Nov 1997.

Int J Pow Elec \& Dri Syst, Vol. 11, No. 2, June 2020 : 1065 - 1073 


\section{BOGRAPHIES OF AUTHORS}

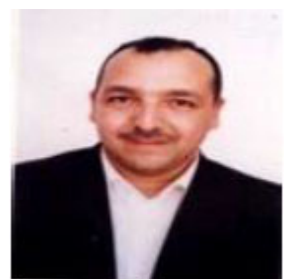

Farah Lotfi received the B.Eng. and Ph.D. degrees in Arabic hand written recognition from the University of BadjiMokhtar Annaba, Algeria, in 1995 and 2000, respectively. From 2000 to 2012, he was a Research Associate with the University of Cherif Messadia, Algeria. He is currently a Research with BadjiMokhtar University in GénieElectromécanique Laboratory, Annaba, Algeria. His current research interests include AI, Fuzzy System, Neural Network and Photovoltaic modeling and control, energy conversion and power electronics. He has authored and co-authored different seminar papers. Dr. Lotfi serves as a Reviewer for international journals in his research field, AI such as Journal of Computer Science USA

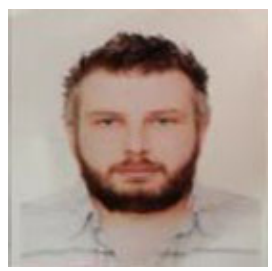

Haddouche Adel born in Moscow on 23 January 1986. He received his master degree in robotics and industrial computing from University of badji Mokhtar Annaba Algeria in 2012, actually he is preparing his thesis in order to obtain a Ph.D. degree in university Larbi tebessi Tebessa Algeria. His current research interests include AI, Fuzzy System, Genetic algorithm, Neural Network, PSO and Photovoltaic modeling and control, energy conversion and power electronics. He has authored and co-authored different seminar papers.

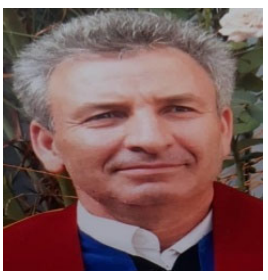

Haddouche ali born in algeria during 1959 he recieved his Ph.D on 1988 then he got his conference master class A on 1993 . on 2009 he earned his professor grade.his research interests are renewable energy, electric security, grid connections ...

He was the Head of electromecanique departement from 2010 to 2016 he has authored and coauthored differents seminar papers and published works during his career. 